\title{
Púrpura trombocitopénica idiopática en el embarazo: a propósito de un caso
}

\author{
Claudia Milena López-López, ${ }^{1}$ (iD Luis Carlos Gerena-Pallares. ${ }^{2}$
}

\begin{abstract}
RESUMEN
La púrpura trombocitopenia idiopática es una patología hemorrágica, caracterizada por la disminución del recuento plaquetario durante la gestación, mediado por células y anticuerpos anti plaquetarios, provocando la destrucción prematura de las plaquetas por el sistema reticuloendotelial, lo que durante la gestación, podría llegar a generar un compromiso del bienestar materno fetal en estadios severos. Esta patología se presenta en 1 de cada 1000 a 10000 embarazos, y corresponde a un 3\% de los embarazos trombocitopénicos. El objetivo del manejo es lograr mantener recuentos plaquetarios dentro rangos seguros, recomendándose iniciar manejo farmacológico cuando se encuentre un recuento plaquetario inferior a 10000 / uL en cualquier momento del embarazo o 30000 / uL en el segundo o tercer trimestre. El caso que se presenta corresponde a una mujer de 40 años, en el primer trimestre del embarazo con antecedente de púrpura trombocitopénica idiopática crónica, con trombocitopenia severa al momento del ingreso al Hospital.
\end{abstract}

Palabras clave: Púrpura Trombocitopénica Idiopática. Embarazo. Plaquetas.

\section{SUMMARY}

Idiopathic purple thrombocytopenia is a hemorrhagic pathology, characterized by a decrease in the platelet count during pregnancy, mediated by cells and anti-platelet antibodies, causing the premature destruction of platelets by the reticuloendothelial system, which during pregnancy could lead to a commitment to maternal fetal wellbeing in severe stages. This pathology occurs in 1 out of every 1,000 to 10,000 pregnancies, and corresponds to $3 \%$ of thrombocytopenic pregnancies. The goal of management is to maintain platelet counts within safe ranges, recommending starting pharmacological management when a platelet count lower than 10,000 / uL is found at any time during pregnancy or 30,000 / uL in the second or third trimester. The case presented corresponds to a 40-yearold woman in the first trimester of pregnancy with a history of chronic idiopathic purple thrombocytopenic, with severe thrombocytopenia at the time of admission to the Hospital.

Keywords: Idiopathic thrombocytopenic purpura. Pregnancy. Blood platlets.

\section{INTRODUCCIÓN}

${ }^{1}$ Especialista en ginecología y obstetricia. Empresa Social del Estado Hospital Universitario San Rafael Tunja. Universidad Pedagógica y Tecnológica de Colombia - UPTC. Tunja, Colombia. ${ }^{2}$ Estudiante de medicina. Grupo de investigación ACEMED-UPTC. Universidad Pedagógica y Tecnológica de Colombia - UPTC. Tunja, Colombia. Autor correspondiente:

Segundo lugar en el primer concurso científico nacional, en el marco del segundo congreso científico nacional FELSOCEM Ecuador, categoría caso clínico (2020). Primer lugar en el segundo concurso científico, en el marco del segundo simposio de actualización medico quirúrgica, Tunja, Colombia, categoría caso clínico (2020). Correo de correspondencia: luis.gerena@uptc.edu.co

Forma de citar este artículo: López-López CM, Gerena-Pallares LC. Púrpura trombocitopénica idiopática en el embarazo: a propósito de un caso. Rev Obstet Ginecol Venez. 2021; 81(4):411-414. https://doi. org/10.51288/00810413
La púrpura trombocitopénica idiopática en el embarazo (PTI), también encontrada en la literatura médica como trombocitopenia inmune primaria (TPI), es una patología hemorrágica, caracterizada por la disminución patológica transitoria o permanente del recuento de plaquetas (1). Es una enfermedad autoinmune adquirida que implica la disminución del recuento de plaquetas mediada por inhibición de la producción plaquetaria por los megacariocitos $(1,2) \mathrm{y}$ por anticuerpos antiplaquetarios dirigidos directamente 


\section{PÚRPURA TROMBOCITOPÉNICA IDIOPÁTICA EN EL EMBARAZO: A PROPÓSITO DE UN CASO}

contra las glucoproteínas plaquetarias GPIIb/IIIa o $\mathrm{GPIb} / \mathrm{IX} / \mathrm{V}$ que provocan su destrucción prematura por el sistema reticuloendotelial, especialmente en el bazo (3), lo que puede generar una trombocitopenia grave $(4,5)$. Una historia previa de PTI agrava la trombocitopenia durante el embarazo (6).

La PTI no es una patología común en el embarazo, su incidencia es de 1 de cada 1000 a 10000 embarazos, y corresponde a un $3 \%$ de los embarazos trombocitopénicos $(1-6)$. En general las pacientes con PTI experimentan una reducción anormal del recuento de plaquetas durante el embarazo $(2,4$ - 6), producida por las inmunoglobulinas maternas de tipo $\mathrm{IgG}$, que pueden atravesar la placenta, pudiendo conducir a una trombocitopenia neonatal y comprometer el bienestar materno fetal $(5,7)$.

El caso que se presenta corresponde a una mujer de 40 años en el primer trimestre del embarazo, con antecedente de PTI crónica, con trombocitopenia grave al momento del ingreso al Hospital Universitario San Rafael de Tunja (HUSRT).

\section{CASO CLÍNICO}

Paciente femenina de 40 años, residente en la ciudad de Sogamoso, Boyacá, Colombia, quien cursaba embarazo de 12 semanas más 3 días, por ecografía de primer trimestre, con formula obstétrica G2P1, un hijo vivo, y antecedente de PTI crónica desde hace 9 años, quien consultó por cuadro clínico de un día de evolución, consistente en aparición de petequias en mucosa oral, la palma de las manos y la planta de los pies y gingivorragia. Refirió haber sido hospitalizada por el mismo cuadro tres semanas previas del ingreso al servicio de obstetricia del HUSRT y, después de manejo con dexametasona, se egresó con prednisolona, $50 \mathrm{mg}$ cada 24 horas.
El reporte del cuadro hemático de ingreso indicó: leucocitos $10600 \mathrm{~mm}^{3}$, neutrófilos 9300/ul, linfocitos 900/ul, hemoglobina $15,4 \mathrm{~g} / \mathrm{dl}$, hematocrito $43,4 \%$, volumen corpuscular medio 91,6 fl, y plaquetas 1000/ ul. Se observó un descenso significativo del recuento plaquetario a pesar del tratamiento con prednisolona.

Fue valorada por los servicios de medicina interna y medicina maternofetal. Se inició tratamiento con un esquema de dexametasona, $40 \mathrm{mg}$ IV cada día por 5 días, se inició inmunoglobulina $\mathrm{G}$ humana en dosis de 1 gramo/kg cada día por 3 días (50 gramos día), y se transfundieron 6 unidades de plaquetas. Se hospitalizó con aislamiento protector.

El recuento de plaquetas postransfusional reportó un ascenso hasta 16 000/uL y en un control en el día dos se observó un aumento hasta $77000 / \mathrm{uL}$. La paciente fue remitida a una institución de cuarto nivel para control de su patología de base.

En la última valoración ecográfica fetal extrainstitucional se reportó un embarazo de 22 semanas más 2 días, por biometría combinada, feto único vivo en situación longitudinal, presentación pélvica, dorso izquierdo, movimientos fetales activos, peso fetal estimado de $494 \mathrm{~g}$, en el percentil 20 para edad gestacional y sexo fetal masculino, no se detectaron alteraciones estructurales ni marcadores de aneuploidia de los detectables a esta edad gestacional. El bienestar fetal estaba conservado en el momento del estudio. También se realizó ecocardiograma fetal que reportó corazón y vasos fetales estructural y funcionalmente normales y un ritmo cardiaco regular durante toda la exploración de 130 a 140 latidos por minuto.

El embarazo continuó hasta la semana 31 de gestación, cuando desencadena un comienzo de trabajo de parto 
espontáneo en su residencia, tiene parto vaginal eutócico y finaliza con un producto único vivo de $1480 \mathrm{~g}$, sexo masculino, que fue ingresado a la unidad de cuidados intensivos (UCI) neonatales por su bajo peso. La paciente no presentó hemorragia uterina en puerperio inmediato. No se cuenta con reporte de plaquetas en el momento del parto.

\section{DISCUSIÓN}

Los riesgos asociados con la PTI en el embarazo siguen siendo controvertidos puesto que el sangrado materno o neonatal grave es poco frecuente cuando un equipo de expertos maneja a embarazadas con esta patología (3), sin embargo estas pacientes deben ser evaluadas cuidadosamente ya que estos embarazos tienen mayor probabilidad de requerir transfusión de plaquetas y obtener recuentos de plaquetas menores a 50 000/ul (5).

El objetivo del manejo de la PTI en el embarazo es lograr y mantener recuentos plaquetarios dentro de rangos de seguridad, más que obtener recuentos en niveles normales (8). Los expertos del panel de la American Society of Hematology (ASH) recomiendan iniciar tratamiento farmacológico al encontrar recuentos de plaquetas inferior a $10000 / \mathrm{uL}$ en cualquier momento del embarazo o $30000 / \mathrm{uL}$ en el segundo o tercer trimestre del embarazo o cuando las pacientes presenten algún tipo de sangrado; adicional a esto recomiendan hacer control semanal de la paciente (2, $4,8)$. El recuento de plaquetas considerado seguro antes de realizar algún procedimiento es de 50 000/uL (8).

El tratamiento habitual de primera línea consiste en prednisolona a dosis bajas de 20 a $30 \mathrm{mg} /$ día durante 2 a 14 días; aunque este medicamento se metaboliza en la placenta por la 11-beta-hidroxilasa, se recomienda no usar dosis altas puesto que pueden tener efectos adversos en el embarazo o en el feto, incluyendo la ruptura prematura de membranas, supresión suprarrenal y un riesgo ligeramente mayor de labio leporino después del uso en el primer trimestre $(4,8)$.

La inmunoglobulina $G$ humana puede utilizarse con o sin corticoides, porque aumenta el recuento plaquetario mucho más rápido, sin embargo no todos los pacientes responden adecuadamente a esta terapia; se recomienda iniciar con dosis de $1 \mathrm{~g} / \mathrm{kg}$ día por 2 días o $400 \mathrm{mg} / \mathrm{kg}$ día por 5 días; en caso de no haber respuesta se considera aumentar la dosis a $2 \mathrm{~g} / \mathrm{kg}$, estas dosis pueden repetirse cuando el recuento de plaquetas cae por debajo de $20000 / \mathrm{uL}(2,4,9)$.

A pesar de los niveles del recuento plaquetario que se presentaron dentro de la gestación, no hubo repercusiones en el crecimiento y desarrollo del producto, reportando un peso 1480 gramos, que corresponde a su edad gestacional, por lo cual fue ingresado a UCI neonatal. La paciente respondió adecuadamente a cada intervención realizada en el HUSRT con dexametaxona e inmunoglobulina G humana y finalizó su gestación con un parto pretérmino espontáneo, sin ninguna complicación para ella.

Se precisa tener un abordaje integral por un equipo que incluya medicina maternofetal y hematología en casos con recuentos de plaquetas bajos durante el embarazo, lo cual es fundamental para evitar consecuencias graves como el sangrado materno o neonatal. El manejo de primera línea se realiza igual que en la paciente no embarazada, con respuestas que alcanzan el $50 \%$ $60 \%$ de éxito en 5 a 7 días (10). En caso de no lograr el objetivo terapéutico con el uso de los corticoides frente a una PTI crónica o en caso de tener un recuento muy bajo que amenace la vida de la paciente, se debe escalar el tratamiento a inmunoglobulina $G$ humana intravenosa, con o sin corticoides, la cual aumenta el recuento plaquetario más rápido.

Conflicto de interés: Los autores declaran que no existen conflictos de intereses. 


\section{PÚRPURA TROMBOCITOPÉNICA IDIOPÁTICA EN EL EMBARAZO: \\ A PROPÓSITO DE UN CASO}

\section{REFERENCIAS}

1. Care A, Pavord S, Knight M, Alfirevic Z. Severe primary autoimmune thrombocytopenia in pregnancy: a national cohort study. BJOG. 2018; 125(5):604-612. doi: 10.1111/1471-0528.14697.

2. Zhao WX, Yang XF, Lin JH. Case of twin pregnancy complicated by idiopathic thrombocytopenic purpura treated with intravenous immunoglobulin: Review of the literature. Niger J Clin Pract. 2017; 20(1):115-118. doi: 10.4103/1119-3077.195540.

3. Wyszynski DF, Carman WJ, Cantor AB, Graham JM Jr, Kunz LH, Slavotinek AM, et al. Pregnancy and Birth Outcomes among Women with Idiopathic Thrombocytopenic Purpura. J Pregnancy. 2016; 2016:8297407. doi: 10.1155/2016/8297407.

4. Cabrera Y, Castillo D. Trombocitopenia en el embarazo: gestacional, inmune y congénita. Rev Cubana Hematol Inmunol Hemoter [Internet]. 2014 [consultado 21 de noviembre de 2020]; 30(3):196-207. Disponible en: http://scielo.sld.cu/pdf/hih/v30n3/hih02314.pdf

5. Fadiloglu E, Unal C, Tanacan A, Portakal O, Beksac MS. 5 Years' Experience of a Tertiary Center with Thrombocytopenic Pregnancies: Gestational Thrombocytopenia, Idiopathic Thrombocytopenic Purpura and Hypertensive Disorders of Pregnancy. Geburtshilfe Frauenheilkd. 2020; 80(1):76-83. doi: 10.1055/a-0865-4442.
6. Al-Husban N, Al-Kuran O. Post-Partum Thrombotic Thrombocytopenic Purpura (TTP) in a Patient with known Idiopathic (Immune) Thrombocytopenic Purpura: a case report and review of the literature. J Med Case Rep. 2018; 12(1):147. doi: 10.1186/s13256018-1692-1.

7. Hott S, Queirolo A, Veas N, Rubio G. Púrpura trombocitopénica idiopática y embarazo. Cesárea versus parto vaginal. Rev Chil Obstet Ginecol. 2006; 71(5):327-332. doi: http://dx.doi.org/10.4067/S071775262006000500006

8. Chosamata BI. The management of immune thrombocytopenic purpura. Malawi Med J. 2015; 27(3):109-112. doi: 10.4314/mmj.v27i3.8.

9. Provan D, Stasi R, Newland AC, Blanchette VS, BoltonMaggs $\mathrm{P}$, Bussel JB, et al. International consensus report on the investigation and management of primary immune thrombocytopenia. Blood. 2010; 115(2):168186. doi: 10.1182/blood-2009-06-225565.

10. Campoverde P, Cuéllar E, Miranda J, Farías M, Rojas A. PTI y embarazo: una experiencia con Rituximab. Rev Chil Obstet Ginecol. 2017; 82(1):80-83. doi: doi. org/10.4067/S0717-75262017000100012

Recibido 16 de diciembre de 2020 Aprobado 10 de marzo de 2021 